\title{
Simple Tool for Energy Analysis of Day Lighting and Artificial Lighting for a Typical Office Building Lighting System Design
}

\author{
Moheet Vishwas, Prashant Kumar Soori*
}

School of Engineering \& Phy sical Sciences, Heriot Watt University Dubai Campus, Dubai, U. A. E

\begin{abstract}
Today, energy shortage and carbon emission are the major challenges faced by all countries. There are many ways to tackle this issue by saving energy in many sectors. Lighting is used in many applications and it is one of the areas to be addressed for imp roving the energy efficiency thereby reducing the energy consumption. In this paper, a typical office building in Dubai is considered for analysis. The first section of the paper reports an efficient use of natural lighting into an office building to improve the energy efficiency. This study is carried out using Simulation software VELUX Daylight Visualizer 2 and simulation results are discussed in detail. The study showed that an ideal office space in Dubai has ample potential to harvest natural light to reduce the need for artificial lighting. In the second section, artificial lighting is used to complement natural lighting to meet the required illumination criteria. DIA Lux 4.1 Lighting Wizard software is used to design and evaluate artificial lighting scheme with similar illumination abilities for the same office space through the use of different types of lamps and the simulation results are highlighted. Its cost effectiveness is also studied. The impact of use of natural lighting and artificial lighting on HVAC system is examined and highlighted.
\end{abstract}

Keywords Artificial Lighting, Fluorescent Lamps, Light Emitting Diode (LED)

\section{Introduction}

Energy consumption is a major concern of global discussions among engineers, scientists and planners. Lighting is one of the sectors of power consumption in residential and commercial buildings. Demand for energy consumption in every country is increasing everyday and there is a scope to improve energy efficiency.

In Dubai, as with the rest of the world, artificial lighting for both functional and decorative purposes is a considerable part of total electrical energy consumed in office buildings although scope of effective utilization of natural lighting is existent. An important issue with few buildings is over-illumination and subsequent cost effectiveness. These costs can be greatly reduced using lighting strategies such as lighting control systems to efficiently harvest day light for indoor lighting purposes. As a result, lighting represents a serious component of energy use today and has attracted a lot of attention, especially in office buildings. The main objectives of this paper are to explore the possibility of optimizing the use of day lighting in the office building and to reduce the energy consumption

* Corresponding author:

pksoori@yahoo.com (Prashant Kumar Soori)

Published online at http://journal.sapub.org/ijee

Copyright (C) 2012 Scientific \& Academic Publishing. All Rights Reserved through the use of artificial lighting while limiting its effects on the cooling load. The ultimate goal is to achieve energy efficiency in lighting system design.

Reducing lighting energy consumption is a major concern for building owners, governments and utilities. A study presented by Nicol, Wilson and Chiancarella (2006, pp.802-813) says that lighting is one of the largest energy users in domestic and commercial build ings[1] and another research presented by Ryckaert et. al. (2010, pp.341-347) concluded that indoor lighting fixtures accounts for 5-15\% of the total electric energy consumption [2]. Governments, utilities and all other building stakeholders have already started implementing strategies to replace existing lighting with more energy efficient lighting sources. In this paper, a typical office space in Dubai in the Middle East is considered for the analysis to find a balance between different strategies that could be used to reduce the electrical lighting energy consumption. The building orientation and local weather conditions were taken into consideration for the effective utilization of day lighting followed by a comparison study of conventional lighting luminaires such as Fluorescent and LED (Light Emitting Diode) lamps. Cost analysis for each technology is discussed. This study can then be used as a baseline to other buildings within this region for further validation.

The structural layout of the office building used for the analysis is shown in Figure 1 and Figure 2 respectively. The 
building has six floors. Each floor has twelve offices of the dimension $7.5 \mathrm{~m}$ length by $5 \mathrm{~m}$ width.

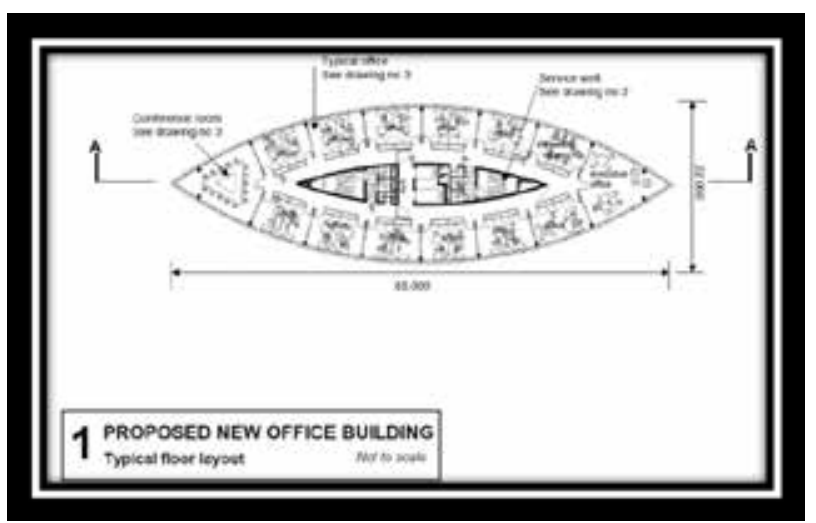

Figure 1. Floor Layout

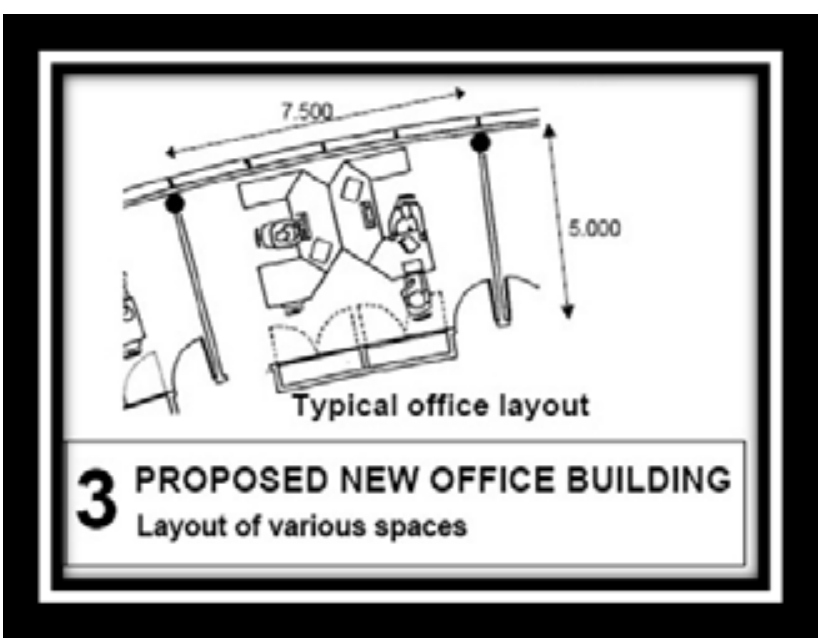

Figure 2. Typical Office layout

\section{Methodology}

Dubai in the Middle East is situated in the Persian Gulf and is the north-eastern state of the United Arab Emirates (UAE). The weather in Dubai is usually warm and sunny because of its closeness to the Tropic of Cancer [3]. Since the Tropic of Cancer line crosses through the United Arab Emirates, the weather in Dubai is hot and humid for a majority of the year. Rainfall is occasional and does not last for a long period. If it does rain, it's mostly in the winter period in the form of short gushes and an occasional thunderstorm. Humidity is over $90 \%$ in coastal areas and an average rain fall of only five days a year in Dubai [3]. Summer season is extremely hot, windy and dry. According to Dubai Meteorological Office website, Dubai has recorded an average high of about $40^{\circ} \mathrm{C}(104 \mathrm{~F})$ and the night lows are about $30^{\circ} \mathrm{C}\left(86^{\circ} \mathrm{F}\right)$, the highest recorded temperature in Dubai is $49^{\circ} \mathrm{C}\left(119{ }^{\circ} \mathrm{F}\right)$ on 27 July 2012. Winters are generally cool but of short duration with an average high of $23^{\circ} \mathrm{C}\left(73^{\circ} \mathrm{F}\right)$ and overnight lows of $14^{\circ} \mathrm{C}(57 \mathrm{~F})$ [4].

The orientation of the building is a major factor in optimizing the building's energy performance. For Dubai, it is recommended that build ing be designed to be oriented on the east-west axis, with any glazing on the north and south sides complemented with appropriate shading and glare control [5]. Shading is another important aspect in the UAE considering the high heat gains experienced through solar radiation. Shading is done through a range of strategies such as planting large trees, building clustering, overhangs or blinds on windows among other shading features. Operable shading devices offer the flexibility through the control of altering shading blades to permit ventilation and day lighting into interior spaces without allowing any direct heat gain [5]. The selection of the facade, the orientation of the building will play a vital part in predicting the thermal gain calculations of the structure.

\subsection{Simulation of Day Lighting Using VELUX Daylight Visualizer 2 Software}

The simulation software VELUX Day light Visualizer 2 is used to evaluate the building's orientation to assess the illuminance levels (lux). The assumption used in this section is that there is no external shading due to neighbouring trees or high rise buildings. This software is used to simulate day lighting conditions and to later provide valuable inputs into the development of an efficient, integrated day lighting strategy.

\subsubsection{Simulation Inputs}

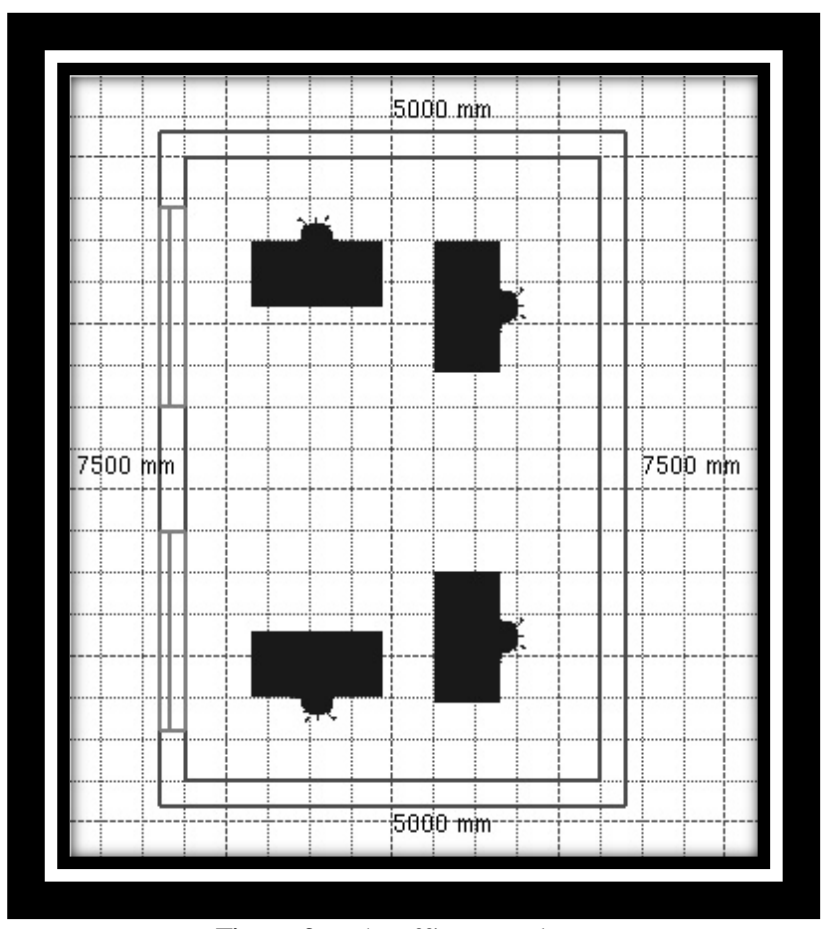

Figure 3. The office space layout

a) Date - The simulation was carried out for events of equinox, March $21^{\text {st }}$ and September $21^{\text {st }}, 2012$.

b) Office space Dimensions -

Length: $7.5 \mathrm{~m}$, Height: $4 \mathrm{~m}$, Width: $5 \mathrm{~m}$, Floor Area: $37.5 \mathrm{~m}^{2}$ and Wall Area: $30 \mathrm{~m}^{2}$

c) Windows - Two windows on the façade of the building. Window Height: 1.8m, Window Width: 2.4m, W indow 
Area: $4.32 \mathrm{~m}^{2}$, Total Window Area: $4.32 \times 2=8.64 \mathrm{~m}^{2}$, Window to Wall Area Ratio: 0.288, Window to Floor Area Ratio: 0.2304 , Height above floor: $0.9 \mathrm{~m}$, Transmittance: 0.78

d) Location - Dubai

Longitude: $55.31^{0}$, Latitude: $28.35^{\circ}$

e) Building Orientation - 250 degrees CW

f) Visib le Transmittance (Tvis)- 0.78

Figure. 3 show the office space and its $3 \mathrm{D}$ view is shown in the Figure. 4.

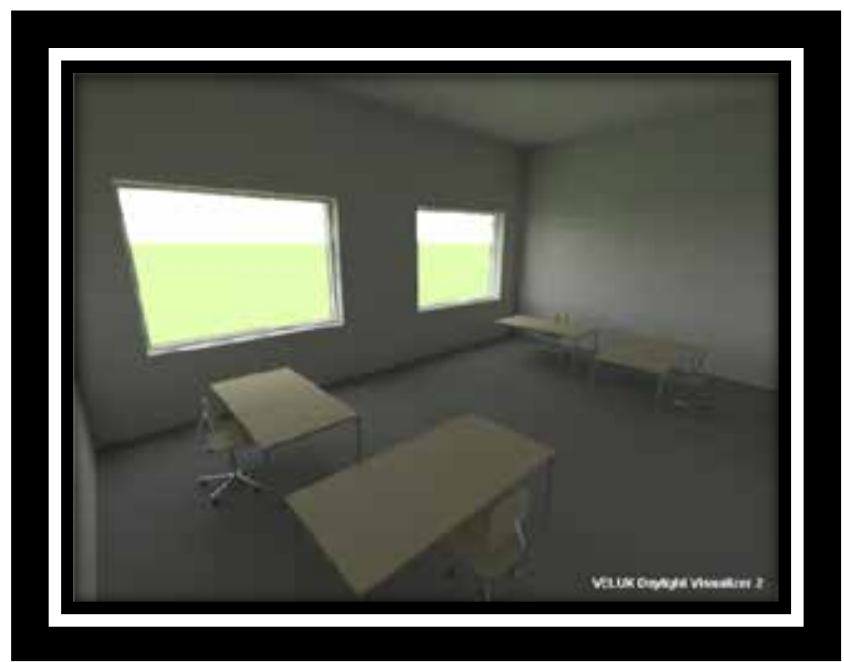

Figure 4. 3D view of the office space layout

\subsubsection{Simulation Results}

Results of the daylight illumination obtained from VELUX for clear sky conditions at 12:00 noon on the equinox (March21/September 21) are shown in Figures 5-8.

The CIBSE Code for Lighting recommends a maintained illuminance of 500 lux for general offices [6].

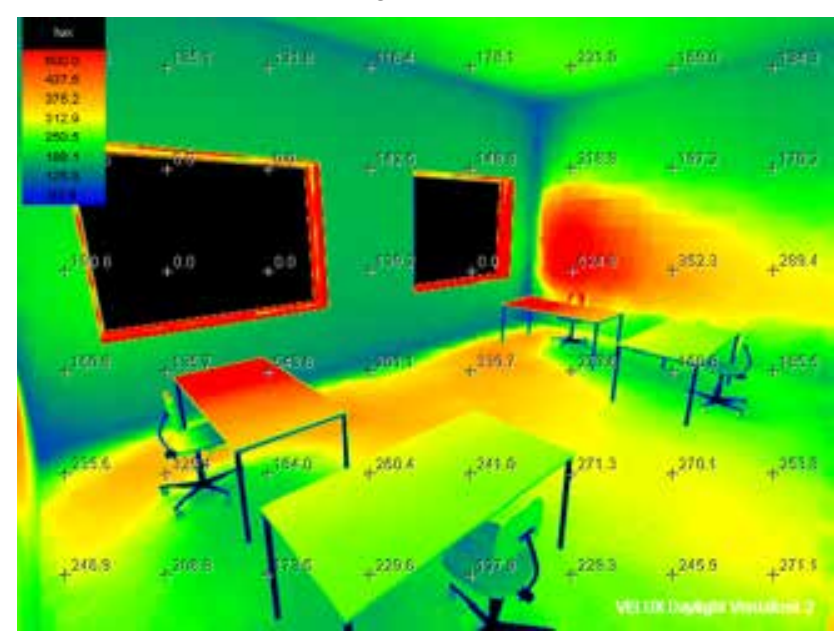

Figure 5. Illumination levels at 12pm on March 21st (Rotation: 312 degrees, Tilt: -15, Height: $2.1 \mathrm{~m}$, Focal length: $22 \mathrm{~mm}$ )

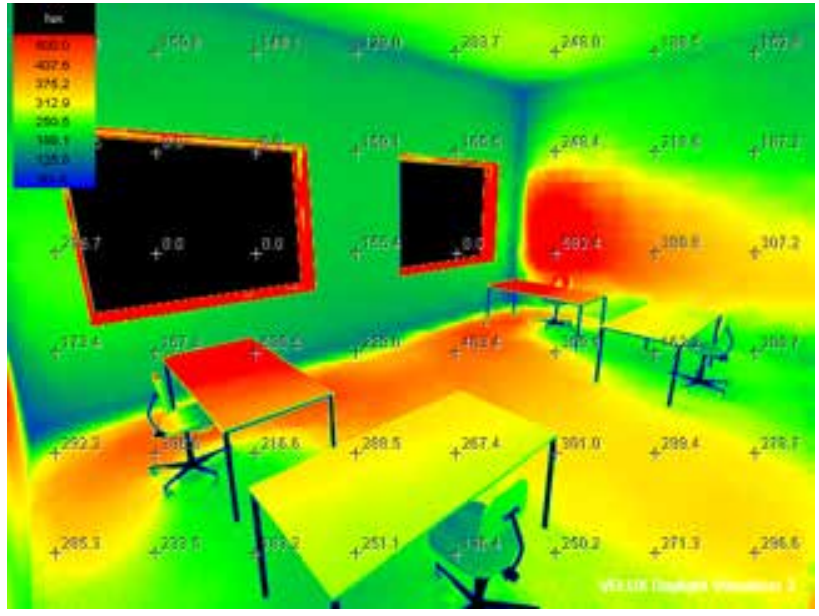

Figure 6. Illumination levels at 12pm on September 21st (Rotation: 312 degrees, Tilt: -15, Height: 2.1m, Focal length: 22mm

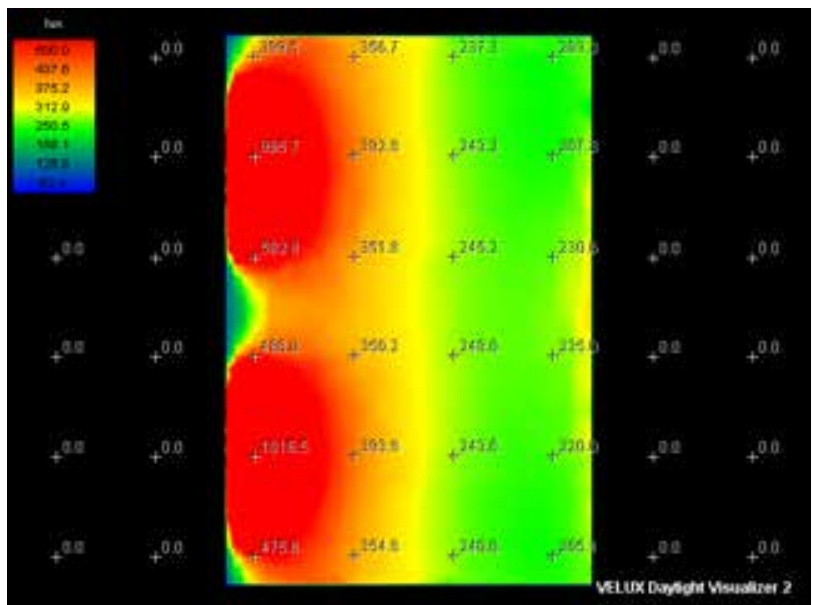

Figure 7. Cross-sectional view of illuminance levels on March 21 at 12 noon (Height $-0.85 \mathrm{~m}$ )

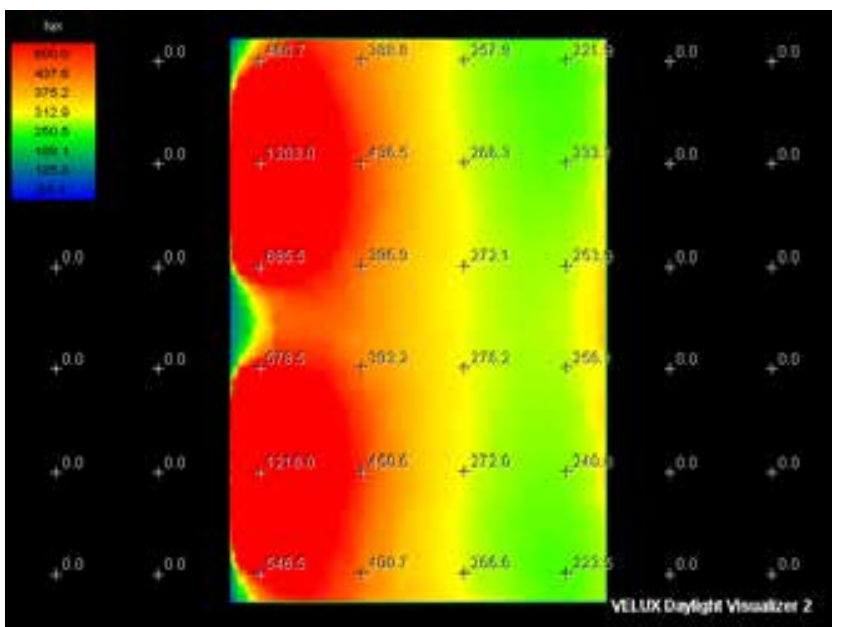

Figure 8. Cross-sectional view of illuminance levels on September 21 at 12 noon (Height $-0.85 \mathrm{~m}$ ) 
The results of the simulation were used to carry out analysis using Green Building criteria (LEED Day light) for optimum daylight within the chosen sample office space [7].

\subsection{Side Lighting Vision Glazing}

Windows located between $0.762 \mathrm{~m}$ and $2.286 \mathrm{~m}$ off the floor (sill height) are considered to be vision glazing. The location of windows in the simulation is $0.9 \mathrm{~m}$ above the floor [7].

\subsection{Visible Transmittance}

Visible light transmittance (VT, Tvis, or VLT) is an optical property that indicates the amount of visible light transmitted. Most Tvis values are between 0.3 and 0.8 . Higher the value, more light is transmitted. A high Tvis is sought to maximize daylight but possible glare problems should be taken into consideration for optimum balance [7]. In this design, the Tvis is 0.78 which is within the acceptable range.

\subsection{Glazing Factor}

Glazing factor is the ratio of interior illu minance at a given point on a given plane (usually the work plane) to the exterior illuminance under known overcast sky conditions. The glazing factor requirement is a minimum of $2 \%$ over $75 \%$ of the regularly occupied areas [7]. Table 1 summarizes the calculations.

$$
\begin{aligned}
\text { Glazing Factor }= & \left\{\frac{\text { Window Area }\left(\mathrm{m}^{2}\right)}{\text { Floor Area }\left(\mathrm{m}^{2}\right)}\right. \\
& + \text { Window Geometry } \\
+\frac{\text { Actual Tvis }}{\text { MinimumT vis }} & \times \text { Window Height Factor }\} \\
= & \frac{8.64}{37.5}+0.1+\frac{0.78}{0.7}+1.4=0.0359
\end{aligned}
$$

\begin{tabular}{|c|c|c|c|c|c|c|}
\hline \multirow{2}{*}{$\begin{array}{l}\text { Regularly } \\
\text { Occupied } \\
\text { Space } \\
\text { Name }\end{array}$} & \multirow{2}{*}{$\begin{array}{c}\text { Regularly } \\
\text { Occupied } \\
\text { Space } \\
\text { Area }\left(\mathrm{m}^{2}\right)\end{array}$} & \multicolumn{2}{|c|}{$\begin{array}{l}\text { Side lighting } \\
\text { Day light ting } \\
\text { Glazing }\end{array}$} & \multicolumn{2}{|c|}{$\begin{array}{c}\text { Side } \\
\text { lighting } \\
\text { Vision } \\
\text { Glazing }\end{array}$} & \multirow[t]{2}{*}{$\begin{array}{l}\text { Glazing } \\
\text { factor }\end{array}$} \\
\hline & & $\begin{array}{l}\text { Area } \\
\left(\mathrm{m}^{2}\right)\end{array}$ & Tvis & $\begin{array}{l}\text { Area } \\
\left(\mathrm{m}^{2}\right)\end{array}$ & Tvis & \\
\hline Office & 37.5 & 0 & & 8.64 & 0.78 & $3.59 \%$ \\
\hline
\end{tabular}

Table 1. Glazing Factor Tabulation Spreadsheet

Total Regularly Occupied Space Surface Area for the entire Floor

$=($ Area of one office space $\mathrm{x} 12)+$ Area of Conference Room + Area of Executive Office

$$
=562.6 \mathrm{~m}^{2}
$$

Total Floor Surface Area $=715 \mathrm{~m}^{2}$

Percentage of regularly occupied space with a 3.59\% glazing is calculated and it is found to be $78.8 \%$. Minimum illuminance on March 21 at 12 noon from Figure 5 is 203.3 lux and minimum illuminance on September 21 at 12 noon from Figure 6 is 221.9 lux.

From the results it is clear that a glazing factor of 3.59\% is achieved in $78.8 \%$ of all regularly occupied areas which is well above the minimum requirement of $2 \%$ for $75 \%$ of regularly occupied area. A minimum daylight illumination level of 203.3 lux has been achieved.

\subsection{Side Lighting Zone}

The value achieved in the proposed design for side lighting zone complies with the LEED requirement $(0.150<$ Window to floor area ratio $\mathrm{x}_{\mathrm{vis}}<0.180$ )[8].

Window to Floor area ratio $=0.2304, \mathrm{~T}_{\mathrm{vis}}=0.78$

$0.150<0.179<0.180$

Hence it is clear from the above result that the proposed design meets the standard.

\subsection{Effective Sky Angle}

Sky Angle is a mount of unobstructed daylight received by the office space. We assume no obstructions at this stage. So, the Effective Sky Angle is $90^{\circ}$ [9].

\subsection{Daylight Factor}

The daylight factor (DF) is a measurement used to quantify the quantity of daylight available in a space. It is measured at the height of the work plane; under a standardized CIE overcast sky. Daylight factor is given by equation (3)[9].

$$
\mathrm{DF}=\left(\mathrm{E}_{\mathrm{in}} / \mathrm{E}_{\text {ext }}\right) \times 100
$$

$\mathrm{E}_{\mathrm{in}}$ : Interior illu minance at a fixed point on the work plane.

$\mathrm{E}_{\text {ext }}$ : Exterior illuminance under an overcast sky.

The 'mean daylight factor' of a room is the average daylight factorvalue of a grid of sensors at work plane height that extends across the room. According to the British Standards Institution, BS 8206 part 2, a space with a mean daylight factor between $2 \%$ and $5 \%$ is considered well lit and requires little or no additional lighting during daytime. A space with a daylight factor of less than $2 \%$ appears dimly lit [10]. VELUX simulation of Daylight factors under overcast conditions are shown in Figure 9 and Figure 10 respectively. Table 2 summarizes the results.

The $\mathrm{DF}_{\text {mean }}$ is much higher than the $\mathrm{DF}_{\text {mean } 0.75}$ because of values taken near the windows. It would be safe to assume the $\mathrm{DF}_{\text {mean } 0.75}$ since it takes the spaces away from the window into consideration to be more accurate.

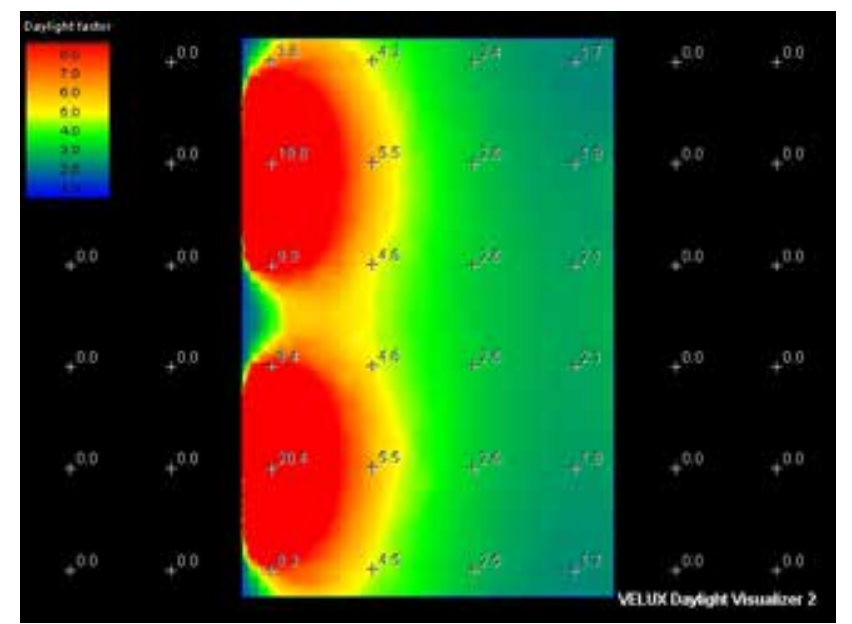

Figure 9. Daylight Fact or at March 21,12 noon under overcast conditions 


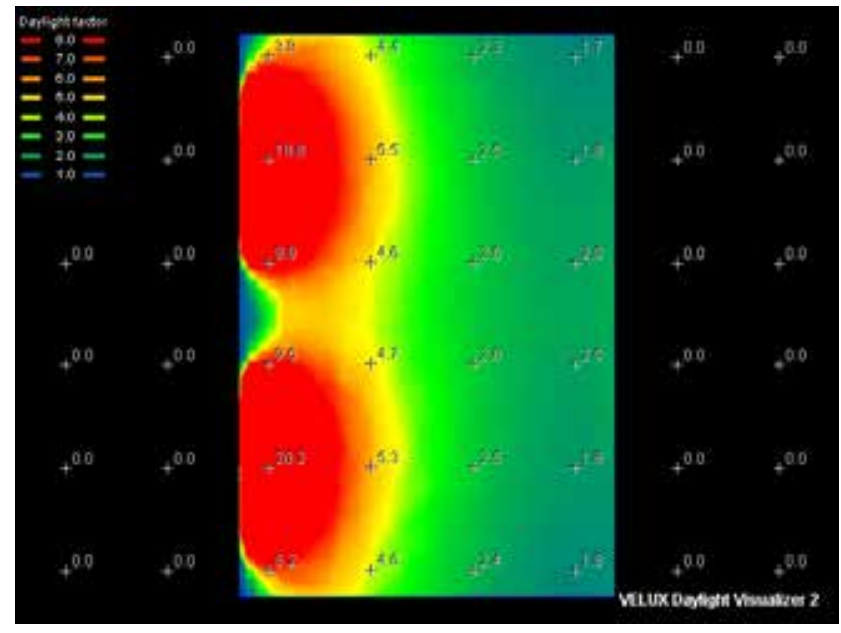

Figure 10. Daylight Factor on September 21, 12 noon under overcast conditions

Table 2. Results of Daylight Factor

\begin{tabular}{|c|c|}
\hline At 12pm on March 21 & At 12pm on September 21 \\
\hline $\mathbf{D F}_{\max }=\mathbf{2 0 . 4}$ (maximum DF) & $\mathrm{DF}_{\max }=20.2$ (maximum DF) \\
\hline $\mathbf{D F}_{\text {min }}=\mathbf{1 . 7}$ (minimum DF) & $\mathrm{DF}_{\min }=1.7$ (minimum DF) \\
\hline $\mathbf{D F}_{\text {mean }}=\mathbf{5 . 3}$ (mean DF) & $\mathrm{DF}_{\text {mean }}=5.27$ (mean DF) \\
\hline $\begin{array}{c}\mathbf{D F}_{\text {mean0.75 }}=\mathbf{2 . 9 4} \text { (mean DF for } \\
\mathbf{7 5 \%} \text { of the area) }\end{array}$ & $\begin{array}{c}\mathrm{DF}_{\text {mean } 0.75}=2.92 \text { (mean DF for } \\
75 \% \text { of the area) }\end{array}$ \\
\hline
\end{tabular}

\subsection{Window to Wall Ratio (WWR)}

The minimum WWR required for a side lit space is given by the equation (4) [9].

WWR $>0.088 \times$ DF $\times 90 \%$ ( sky angle $)$

The recommended DF minimum is $2 \%$, sky angle is assumed to be $90^{\circ}$ and the WWR in the office space dimensions is 0.288 . Therefore the above calculation shows that the minimum WWR of 0.225 for a side lit space has been satisfied.

\subsection{Dimensional Constraints - Daylight Unifor mity/ Limiting Depth}

It is the distance at which the uniformity of daylighting levels drops throughout the space. Limiting depth can be calculated using equation (5) [9].

$$
\text { Limiting Depth }=\frac{2}{1-\text { Rmean }} /\left(\frac{1}{\mathrm{~W}}+\frac{1}{\mathrm{H}}\right)
$$

$\mathrm{R}_{\text {mean }}=$ Mean Surface Reflectance $($ Floor $=0.62$, Wall $=$ 0.71 , Ceiling $=0.84), \mathrm{W}=$ Wall width in $\mathrm{m}, \mathrm{H}=$ Window head height in $\mathrm{m}$.

Limiting Depth $=\frac{2}{1-0.723} /\left(\frac{1}{7.5}+\frac{1}{2.7}\right)=14.4 \mathrm{~m}$

Spaces with depths lower than this limiting depth show relatively uniform levels of daylight throughout. As per calculation, the max limiting depth is $14.4 \mathrm{~m}$ while the proposed office space depth is $5 \mathrm{~m}$.

Thus, from the simulation results it is evident that the office space designed is ideal for day lighting as it meets the required standards. The intent is not only to harvest day lighting but also to provide the building occupants a connection between indoor spaces and the outdoors through the introduction of daylight and views into the regularly occupied areas of the buildings.

\section{Simulation of Indoor Lighting}

This section deals with the artificial lighting to supplement the day lighting for the selected office space. The DIA Lux Light Wizard software is used for analysis of the indoor lighting schemes using both Fluorescent and LED lu minaries. It is assumed that the offices are lit by artificial light sources throughout normal office hours (9A.M to 5P.M) without harvesting the day light. The illuminance level of 500 lux as per CIBSE Code for lighting offices is used for the analysis [6], [12].

The following luminaries were chosen for analysis because of their similar illumination ability:

\subsection{Fluorescent luminary -TL 5000 5506/236/6/EB (Make, GE)}

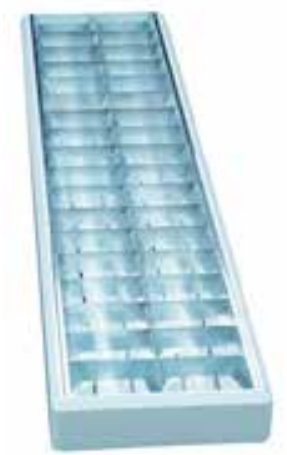

Figure 11. Fluorescent Luminaire

The office room is illuminated through the use of GE make fluorescent lamps TL 5000 5506/236/6/EB. Figure 12 shows the polar candela of the luminaire. Figure 13 shows DIALux 4.1 simulation results with fluorescent luminary -TL 50005506/236/6/EB.

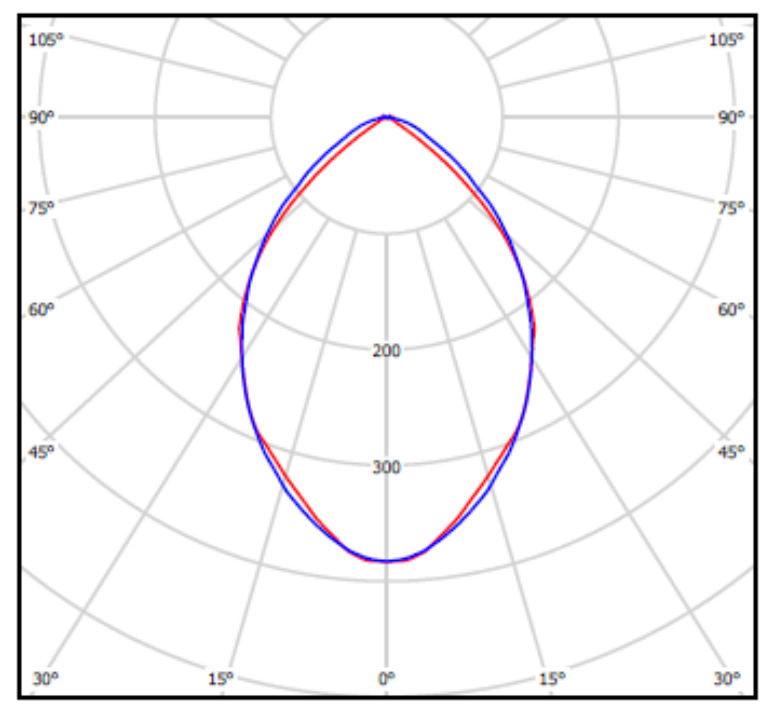

Figure 12. Polar Candela of the lamp 


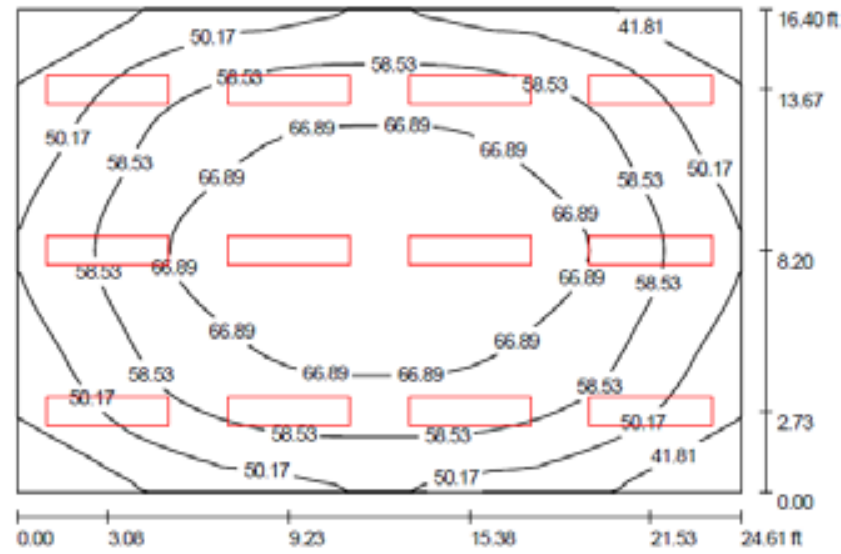

Figure 13. Simulation Results with Fluorescent luminaire. (The indicated values are in foot-candles)

It is clear from this result that twelve fittings were required to illuminate the office space to achieve the recommended lux level of 500 .

\subsection{LED Luminary - ENDO GXLX7009W of (Make, ENDO)}

The office room is illuminated through the use of LED Lamps ENDO GXLX7009W. Figure 15 shows the polar candela of the luminaire. Figure 16 shows DIALux 4.1 simulation results with LED luminary. Wattage is $125 \mathrm{~W}$, Luminous flux is 6279 lumen.

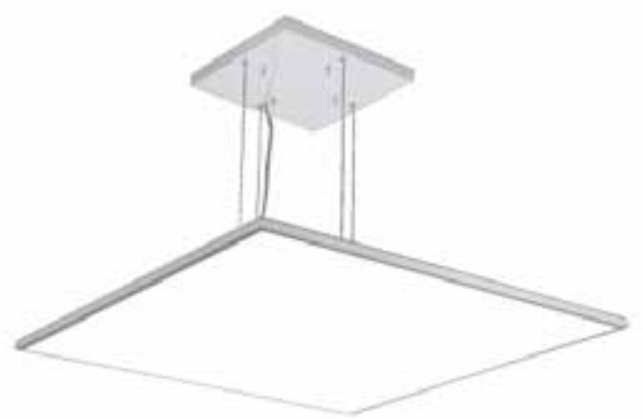

Figure 14. LED Luminaire

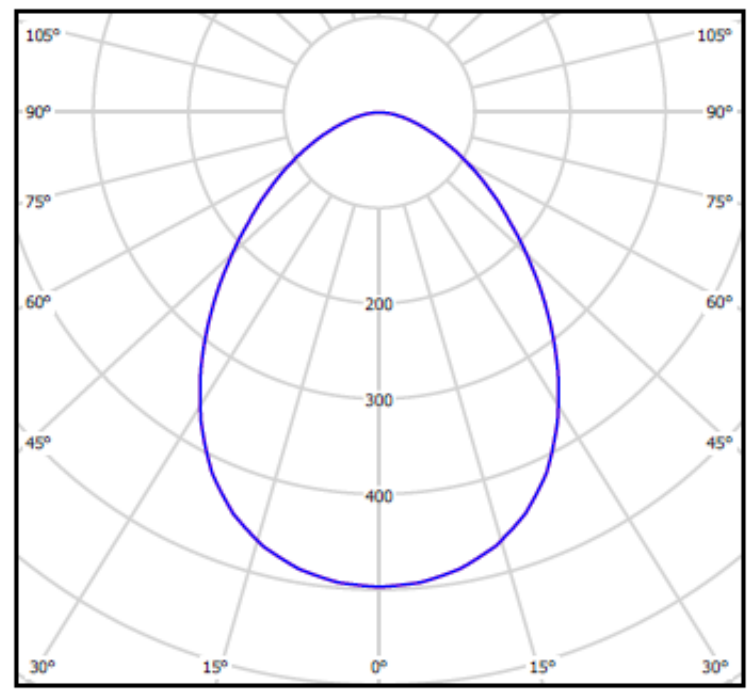

Figure 15. Polar Candela of the LED Lamp

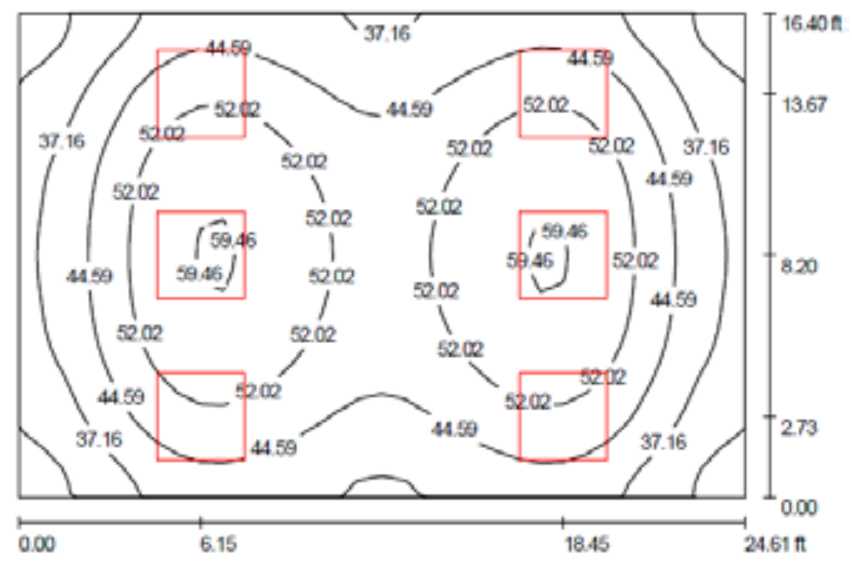

Figure 16. Simulation Results with LED luminaire. (The indicated values are in foot-candles)

It is clear from th is result that six fittings were required to illuminate the office space to achieve the recommended lux level of 500.

Computer simulations of both the lighting levels in the office space are obtained using the DIAlux Lighting Wizard software and the results are summarized in the Table 3 . The maintenance factor was as sumed to be 0.67 . The power tariff and fuel surcharge in Dubai as of June 2012 are 23 fils/kWh and 6 fils/kWh respectively. These values are used for the calculation purposes and the results are tabulated in Table 3.

Table 3. Summary of Results of DIALux Simulation

\begin{tabular}{|c|c|c|}
\hline Details & $\begin{array}{c}\text { Fluorescent } \\
\text { Luminaire }\end{array}$ & $\begin{array}{c}\text { LED } \\
\text { Luminaire }\end{array}$ \\
\hline $\begin{array}{c}\text { Number of Luminaires } \\
\text { required }\end{array}$ & 12 & 6 \\
\hline $\begin{array}{c}\text { Ave rage Illuminance - } \\
\text { EAVE }\end{array}$ & 624 lux & 505 lux \\
\hline $\begin{array}{c}\text { Minimum Illuminance } \\
\text { - EMIN }\end{array}$ & 376 lux & 279 lux \\
\hline $\begin{array}{l}\text { Maximum Illuminance } \\
\text { - EMAX }\end{array}$ & 807 lux & 656 lux \\
\hline $\begin{array}{c}\text { Uniformity Ratio - } \\
\text { EMIN/ EAVE }\end{array}$ & 0.60 & 0.56 \\
\hline $\begin{array}{l}\text { Uniformity Ratio - } \\
\text { EMIN/ EMAX }\end{array}$ & 0.47 & 0.43 \\
\hline $\begin{array}{l}\text { Total Luminous flux of } \\
\text { all Luminaires in the } \\
\text { office space }\end{array}$ & 80.4 Klum & 37.674 Klum \\
\hline $\begin{array}{l}\text { Total power consumed } \\
\text { by all Luminaires in } \\
\text { the office space for a } \\
\text { month }\end{array}$ & $214.27 \mathrm{kWh}$ & $186 \mathrm{kWh}$ \\
\hline $\begin{array}{l}\text { Annual Energy Costs } \\
\text { for a single office space }\end{array}$ & 591.38 AED & 513.36 AED \\
\hline $\begin{array}{l}\text { Annual Fuel Costs for a } \\
\text { single office space }\end{array}$ & 154.27 AED & 133 AED \\
\hline Total Annual Costs & $745.65 \mathrm{AED}$ & 646.36 AED \\
\hline
\end{tabular}

\section{Results and Conclusions}

A typical office space in Dubai in the Middle East is considered for the analysis to find a balance between different strategies that could be used to reduce the electrical 
lighting energy consumption. The building orientation and local weather conditions were taken into consideration for the effective utilization of day lighting using VELUX Daylight Visualizer 2 software followed by a comparison study of conventional lighting luminaires such as Fluorescent and LED (Light Emitting Diode) lamps.

The office space was designed to meet day lighting harvesting criteria for Dubai. The intention being not only to harvest day lighting but also to give the building occupants a connection between indoor spaces and the outdoors through the introduction of daylight and views into the regularly occupied areas of the buildings. It is evident from the VELUX simulation results that the office space designed is ideal for day lighting as it meets the required standards.

The DIA lu x Light Wizard software is used for analysis of the indoor lighting schemes using both Fluorescent and LED luminaries. If Fluorescent Luminaires are used for interior illumination throughout working hours, the annual operating costs would be around 745.65 AED (Arab emirates Dirhams) for a single office space. There are twelve offices in a single floor, which brings the cost to be around 8950 AED (approximately). If the LED luminaires are used, the operating costs would be about 646.36 AED and the annual cost for a single floor comes around 7756 AED (approximately). The difference between both the costs is 1194 AED for a single floor and the building has five floors typical to the one in consideration, this brings the figure to approximately $6000 \mathrm{AED}$, quite a substantial amount in terms of savings just through operating costs and this being a liberal estimate. The savings through the LED light fixtures can increase even more through the option of controls.

With effective use of thermal insulation and thermal automation controls the use of day lighting can have no or the least impact on the space cooling system within the building. Hence a control strategy with control logic and coupling algorithm to integrate the lighting and space cooling system was recommended for practical implementation and further validation of this study. The idea is to create a baseline study for an ideal office space which can then be used as a reference while being applied to other buildings in Dubai or Middle East in general. This study can be discussed further by establishing mathematical equations to couple daylight harvesting and space cooling. This will also contribute towards Green building practices and help in cutting down the energy consumption and lower the $\mathrm{CO}_{2}$ emissions.

\section{REFERENCES}

[1] Nicol, F.,Wilson M. and Chiancarella C. (2006) Using field measurements of desktop illuminance in European offices to investigate its dependence on outdoor conditions and its effect on occupant satisfaction, and the use of lights and blinds: Energy and Buildings

[2] Ryckaert W., Lootens C., Geldof J. and Hanselaer P. (2010) Criteria for energy efficient lighting in buildings: Energy and Buildings.

[3] Dubai Geography (2012)[online]. Available from http://www.dubai.com/v/geography.html (Accessed June 2012)

[4] Dubai Meteorological Office (2012)[online]. Available from http://www.dia.ae/dubaimet/ (Accessed June 2012)

[5] Passive Cooling (2012)[online]. Available from http://www.carboun.com/sustainable-development/sustainabl e-design/passive-cooling-resp onding-to-uae\%E2\%80\%99s-s oaring-electricity-demand/ (Accessed June 2012)

[6] CIBSE (2012)[online]. Available from http://www.cibse.org /index.cfm?go=page.view\&item $=453 \# 4$ (Accessed June 2012)

[7] Green Building Studio (2012)[online]. Available from http://docs.autodesk.com/GBS/4.2UX/ENU/GBS\%20User\% 20Documentation/index.html?url=./files/WS73099cc142f48 755-385a98b0121d1bb015f-1443.htm,topicNumber=d0e287 8 (Accessed June 2012)

[8] U.S. Green Building Council (2012)[online]. Available from https://www.usgbc.org/ShowFile.aspx?DocumentID=9377 (Accessed June 2012)

[9] Day Lighting Rules of Thumb (2009)[online]. Available from http://www.gsd.harvard.edu/research/gsdsquare/Publications /DiffuseDaylightingDesignSequenceTutorial.pdf (Accessed June 2012)

[10] British Standards Institution (2012)[online]. Available from http://www.cibse.org/pdfs/GPG245.pdf (Accessed June 2012)

[11] Safaa Alzubaidi, and Prashant Kumar Soori, "Energy Efficient Lighting System Design for Hospitals Diagnostic and Treatment Room- A Case Study" in the Journal of Light \& Visual Environment, The Illuminating Engineering Institute of Japan, Vol.36, No.1, pp. 23-31, April 2012. ISSN 0387-8805, H-Index:6

[12] Prashant Kumar Soori, and Safaa Alzubaidi, "Study on Improving the Energy Efficiency of Office Building's Lighting System Design" in the Proc. of the 6th IEEE GCC Conference, February 19-22, 2011, Dubai, U.A.E, ISBN:978-1-61284-118-2, Digital Object Identifier: 10.1109/IEEEGCC.2011.5752604, Date of Current Version: 19 April 2011, pp. 585-588. 